\title{
A lot like the other: Parents' consumer responses to brand-modified product placements in children's programming
}

\section{бopen AcCess}

Peer-reviewed article

Citation: Gong, Z., \& Holiday, S. (2021). A lot like the other: Parents' consumer responses to brandmodified product placements in children's programming. Journal of Media Literacy Education, 13(1), 4155. https://doi.org/10.23860/JMLE2021-13-1-4

Corresponding Author:

Zijian Gong

harrison.gong@ttu.edu

Copyright: $\odot 2021$ Author(s). This is an open access, peer-reviewed article published by Bepress and distributed under the terms of the Creative Commons Attribution License, which permits unrestricted use, distribution, and reproduction in any medium, provided the original author and source are credited. JMLE is the official journal of NAMLE.

Received: November 15, 2019

Accepted: October 1, 2020

Published: May 24, 2021

Data Availability Statement: All relevant data are within the paper and its Supporting Information files.

Competing Interests: The Author(s) declare(s) no conflict of interest.

\author{
Zijian Gong \\ Texas Tech University, USA \\ Steven Holiday \\ University of Alabama, USA
}

\begin{abstract}
This research examined whether parents can recognize modified brands in children's programming, and whether program educational value and active mediation intention would moderate perceptions of modified brand references. An experiment was conducted with 109 parents of child(ren) between 3-6 years old. Participants watched clips that systematically varied in brand reference type (i.e., actual v. modified brands) in product placements and program educational value. Results indicated modified brands were as recognizable as actual brands. Product placements in high educational value programs were less recognizable but generated more positive attitudes toward the brand than product placements in low educational value programs. The active mediation intention level moderated recognition and purchase intention of brands referenced in children's programming, and the negative perceptions of product placements were most salient when actual brands were used in low educational value programs. The practical implications for advertising and media practitioners were discussed.
\end{abstract}

Keywords: brand modification, mediation intention, children, educational value.

\author{
Journal of Media Literacy Education \\ THE OFFICIAL PUBLICATION OF THE \\ National AsSOCiation for MEdia literacy Education (NAMLE) \\ Online at www.jmle.org
}




\section{INTRODUCTION}

Product placement is one of the most common advertising strategies that purposefully incorporates brands with editorial content to sell a product (Kamleitner \& Jyote, 2013). The U.S. advertising expenditure on product placements expanded to 11.44 billion dollars in 2019 as product placements provide a high brand-program integration to ensure that viewers cannot skip the advertising messages or references to the product (Statista, 2020). Alongside this growth is the increasing popularity of using product placements in children's programming (Naderer et al., 2019).

While product placements have become a very common form of advertising practice in children's programs, several bodies of research have raised concerns. This discussion has encompassed the use of well-known program heroes and popular media figures to elicit brand-favorable attitudes toward products from children (Campbell, 2006). One of the first studies that examined product placements in children's programming showed when children aged between three and seven years old watched The Flintstones, one-fourth of the children recalled the Flintstones eating cereal during the cartoon and showed a greater desire for the actual cereal product (Atkin, 1975; see also, Kamleitner \& Jyote, 2013).

Several pieces of proposed legislations have been made in Congress to prohibit certain forms of advertising in children's programs that are deceptive and unfair, yet the focus was mainly on advertising using popular children's characters (Campbell, 2006), and regulation in this area remains largely self-imposed by brands in the United States (Enright \& Eskenazi, 2018). Particularly concerning among other forms of advertising targeting children, may be the use of brandmodified references in children's programs - product placements using modified brands that share a high level of similarity with existing brands.

Parents usually serve as media gatekeepers for children's advertising exposure because children do not reliably have a refined ability to critically evaluate advertising (Buijzen, 2009, 2014). With this responsibility, parents, researchers, and advocacy groups are committed to identifying how advertisers target children with product placements and what effects this practice has on young audiences (e.g., Enright \& Eskenazi, 2018). Research has suggested, however, that while parents may be motivated to address the practice with their children (i.e., active parental advertising mediation; Buijzen, 2014), they may have a limited capacity to readily identify product placements in contemporary children's media (Spiteri Cornish, 2014). Furthermore, although those placements may not be readily recalled, parents do encode them for later retrieval through recognition (Holiday \& Davies, 2018). Parents' recognition and response to product placements in children's media are salient variables to address, because parental interventions (i.e., mediation) may be dependent on their literacy of this form of advertising (Mendoza, 2009; Spiteri Cornish, 2014). Those interventions that parents have with their children about advertising can limit advertising's effects on their children (Bijmolt, Claasen, \& Brus, 1998) by building children's literacy about advertising and making them more informed, critical consumers of advertising content (Rozendaal et al., 2016). While prior research has examined parents' perceptions of product placements, the practice's unique application in children's educational contexts (Araque-Padilla et al., 2019), often under a brand-modified guise (Petty, 2009) is a pressing area of needed research. The present study seeks an understanding of whether brand-modified product placements are received and perceived by parents similarly to product placements that use actual brands. Such research could carry very salient implications for practitioners, media producers, activists, and legislators.

\section{Modified brand reference in product placements}

The persuasive effect of product placements on children is well documented in prior empirical research, with indications of a strong influence on recall, perceptions, and selection of the integrated products (Elliott, 2009; Hudson \& Elliott, 2013). Product placements have become increasingly sophisticated in children's programs, with products or brands being woven into storylines, visual narratives, games, or song lyrics.

One particular type of product placement that calls for research attention is brand-modified product placement, in which the branding information (i.e., logo) in product placements is altered out of lack of permission to use the products, lack of desire to affiliate the program with the product corporation, or for legal and entertainment purposes (Petty, 2009). Most of the brand modification is achieved through imitation by directly imitating distinctive perceptual features of an existing brand such as font, shape, and color scheme to create a modified brand that shares a high level of similarity with an existing brand, a practice that is very 
similar to copycat brands (Van Horen \& Pieters, 2012). For example, in the movie Shrek 2, the Starbucks brand is modified into "Farbucks."

A key question yet to be addressed is whether brandmodified product placements are as recognizable as the actual brands they resemble. Prior research from the perspective of schema theory suggests that modified brands should be recognized as the existing brands instead of being perceived as distinctive new brands. A schema represents pre-existing cognitive structures based on conceptual and experiential knowledge that ties information about any given event together (Lord \& Foti, 1986).

The essence of schema theory is that perceptions of new information are dramatically influenced by existing schemata. The assimilation of new information is facilitated when it fits existing schemata, while new information that is incongruent or contradicts existing schemata will be reinterpreted or distorted to fit existing schemata (Rumelhart, 1980). Schema theory and research conducted through its lens have empirically demonstrated the impact of schemata in various contexts such as reading comprehension (Carrell \& Eisterhold, 1983) and perceptions of inconsistent or negative feedback. The advertising literature has also applied schema theory in the examination of perceived congruence between spokesperson and product (Lynch $\&$ Schuler, 1994) and the persuasive impact of brand advertisements that incorporate social issues (Schmidt \& Hitchon, 1999).

From the perspective of schema theory, past experiences with branding information supply us with expectations and frameworks to make sense of modified brands. When new information (i.e., modified brands) is incongruent with existing schemata (i.e., perceptions of an actual brand), individuals will assimilate the incongruent information into an existing schema (Rumelhart, 1980).

Additionally, although modified brands contain elements that are distinctive or incongruent with existing brands, brand modification is usually achieved by directly imitating distinctive perceptual features of existing brands. These distinctive perceptual features help tie the connection between the modified brand and the actual brand and facilitate the integration of modified brands into the existing brand schema. Thus, this research hypothesizes that target brands will be as recognizable in product placements using modified brands as in product placements using actual brands (Hypothesis 1).

\section{Program educational value and perceptions of product placements}

Prior literature demonstrates that audience response to product placements are complicated and vary by individual factors (De Gregorio \& Sung, 2010). Some studies have long asserted that viewers predominantly respond positively to the practice, especially when they notice the brands they use are featured in a scene or used by a movie character (DeLorme \& Reid, 1999; Ong, 1995). Research that does recognize negative responses is often based on objections to ethically-charged product placements (Hudson et al., 2008) and has motivated legislative efforts to regulate the practice through disclosures (Campbell, 2006; see Evans et al., 2018). Research on consumer effects of product placements has focused on placement format (DeLorme \& Reid, 1999), positive beliefs about the media (Gould et al., 2000), and involvement (Nicovich, 2005). Results suggest that product placement evaluations may be related to demographic factors such as gender, race, and age (De Gregorio \& Sung, 2010). Additionally, audience evaluation of the specific medium vehicle in which the brand was placed was significantly correlated with product placement evaluations (Van Reijmersdal et al., 2005).

Product placements are becoming notably present in children's programming that is educational in nature (Araque-Padilla et al., 2019). The emergence of product placements in this context may reasonably affect evaluations of product placements. The Expectancy Violation Theory (EVT) argues that individuals hold a certain set of expectations for interpersonal relationships, communicator characteristics, and communication contexts (Burgoon, 1993). Expectancy violation occurs when a behavior or message deviates from expectations, which prompts individuals to evaluate the violation as positive or negative. Violations that result in positive outcomes are evaluated as positive violations and usually result in positive emotional reactions and communication outcomes; whereas, violations perceived as worse than expectations are deemed as negative violations that result in negative responses and remediation behaviors (Burgoon, 1993).

The concept of expectancies is directly relevant to perceptions of product placements in educational content. Prior research suggests that the impact of product placements likely depends on the context in which the brand appeared (Van Reijmersdal et al., 2005). In the context of children's programs, parents hold the expectation that educational programs should 
contribute to the learning and development of their children. As evidenced in recent survey results, parents were not concerned about children's screen-time when they perceived screen-viewing to be a good educational resource (He et al., 2005). Most parents expect that the content in educational programs should provide academic knowledge such as math and literacy, or teach social or emotional skills. Therefore, parents' expectations for educational programs usually do not include information that serves commercial purposes, including product placements, and when they experience it within the context of educational content, they are generally opposed to the practice (see Kirkpatrick, 2000). Negative expectancy violation should occur when product placements are incorporated in educational programs, resulting in a more negative evaluation of the brand. Thus, the present study proposes that product placements in high educational value programs will be less recognizable and predict more negative attitudes toward the brand than product placements in low educational value programs (Hypothesis 2).

\section{Active mediation intention and brand reference}

Parents have historically responded to advertising messaging that targets their children by becoming more involved in their children's media use and communicating with their children about the nature and purpose of advertising (Buijzen, 2014). Such parental interventions can effectively limit advertising's effects on children (Bijmolt et al., 1998; Rozendaal et al., 2016). When those interventions, known as parental advertising mediation are active in nature, parents use discussions about the content and its persuasive outcomes to guide their children's recognition and critical evaluation of the message (Buijzen, 2014). The active parental advertising mediation approach is effective at stimulating children's awareness of the production process (Mendoza, 2009) and the purpose and intent of advertising (i.e., advertising literacy; Rozendaal et al., 2016).

Adults themselves are naturally suspicious of ulterior, persuasive motives of messaging (Main et al., 2007). Additionally, parents, in particular, are generally motivated to scrutinize media to protect their children from advertising exposure and its influence (Buijzen, 2009). Furthermore, parents who employ active mediation techniques are critical evaluators of media messages (Rasmussen et al., 2016). Given this, it is a reasonable assumption that product placements will be more likely to be noticed by parents who intend to actively mediate a particular type of advertising.

Within the present context of modified brands, adults who approach the manipulated message with a critical perspective may experience them as a type of metaphor. With metaphors in persuasive messaging, individuals experience some amount of dissonance in the discrepancy between the manipulated image and its likeness to the actual counterpart, have a desire to resolve the metaphor, devote cognitive resources to its resolution, and feel a sense of satisfaction and accomplishment when they resolve the metaphor (Mohanty \& Ratneshwar, 2015). This process positively influences affective and cognitive brand-favorable responses in viewers (Han, 2018).

The EVT suggests that the valence of expectancy violation is determined by the magnitude of the violation and whether the violation is less or more favorable than the expectation. While the magnitude of violation of expectations for children's programming is less when modified brands are featured rather than actual brand references, modified brands also could compel viewers to resolve the visual metaphor and thus lead to a more positive evaluation of the brand references, especially among parents who employ active mediation techniques. Taken together, it is reasonable to hypothesize that parents who have intentions to provide active mediation in response to viewing a product placement would employ a critical evaluation of modified brand information in product placements , engage in resolving the metaphor, recognize the actual brand, and experience brand-favorable attitudes upon resolving the modified brand into the actual brand. By combining this literature with the previous literature and hypothesis that the modification of brands would not make depicted brands any more or less recognizable, the present research also hypothesizes active mediation intention will moderate the impact of brand reference type on attitude toward the brand. Specifically, parents with a higher level of active mediation intention will have more positive attitudes toward product placements using modified brands than product placements using actual brands (Hypothesis 3a).

Alternatively, parent audiences who do not have an intention to actively mediate the content are likely not critically evaluating the message as they receive it (Rasmussen et al., 2016). If they are engaging in children's content with their children, parents may be actively seeking out content that is enjoyable to them as well as to their children (Nikken \& Jansz, 2014). When these individuals (i.e., adults) are consuming media for 
personal enjoyment, they appreciate the realistic use of product placements and feel that they enhance the narrative in which they are featured (Balasubramanian et al., 2006; DeLorme \& Reid, 1999). Therefore, the present study also proposes that parents with a lower level of active mediation intention will have more positive attitudes toward product placements using actual brands than product placements using modified brands (Hypothesis 3b).

\section{Active mediation intention and program educational value}

Active parental mediation also plays an important role in the processing of educational media content, where it can help facilitate children's development of abstract and reflective thinking, vocabulary, visuomotor coordination, and letter and number learning (Reiser et al., 1988). It should come as no surprise then, that some parents deliberately engage with educational content so they can understand it and work with their children to master it and attain academic achievement (Ma et al., 2016). Generally, parents who conscientiously consume media have a greater likelihood of providing active mediation (Rasmussen et al., 2016), which is in agreement with the notion that mediation is the manifestation of literacy (Mendoza, 2009). Given that parents are already generally motivated to scrutinize media and ensure that children are protected from advertising exposure and its influence (Buijzen, 2009), when product placements are combined with educational content, one should expect that parents who intend to provide active mediation in this environment should be doubly vigilant and recognition of advertising that occurs in this programming should be much stronger than when the content is not perceived to be educational in nature.

Additionally, advertising in educational content has a history of escaping parents' critical evaluations or being excused for their prosocial purposes (Holiday, 2018), and literature even recognizes that some parents are conscientious supporters of product placements when they are used to enhance attention and engagement with educational content (see Kirkpatrick, 2000). This recognition that the practice of product placement is happening is also compounded, in adults, with an open recognition and admission that the practice also influences purchasing decisions and brand preferences (DeLorme \& Reid, 1999). Because active mediation intention will moderate the impact of program educational value on brand recognition and attitude, it is reasonable to hypothesize that parents with a higher level of active mediation intention will have better recognition and more positive attitudes toward product placements in high educational value programs than product placements in low educational value programs (Hypothesis 4a).

Alternatively, when parents do not have an intention to actively mediate programming content, it may stem from a lack of vigilance in their viewing behavior (Rasmussen et al., 2016), but it may also be a product of a lack of literacy for the type of advertising integration in the programming (Mendoza, 2009; Spiteri Cornish, 2014). When such is the case, as discussed previously, these parents may not expect the presence of advertising in educational programming. Indeed, their engagement with the educational content and focus on their children's learning may be cognitively demanding enough that the product placements escape recognition. Thus, we would hypothesize that parents with a low level of active mediation intention will have better recognition and more positive attitudes toward product placements in low educational value programs than product placements in high educational value programs (Hypothesis 4b).

The literature reviewed to this point regarding product placements and active parental advertising mediation allows for a hypothesis that for individuals with greater intention to engage in active mediation, the use of modified product placements is more positively received. Also, the pairing of product placements with educational programming among this population (i.e., those with active mediation intentions) should yield more recognition of the advertising effort. Without an educational context or a visual metaphor to resolve, this population, who have intentions to provide active mediation of the product placements, are more averse to product placements when they are received through educational programming and use actual brands. Thus, we propose that the negative perceptions of product placements will be most salient when participants with a high level of active mediation intention evaluate actual brands in low educational value programs (Hypothesis $5)$. 


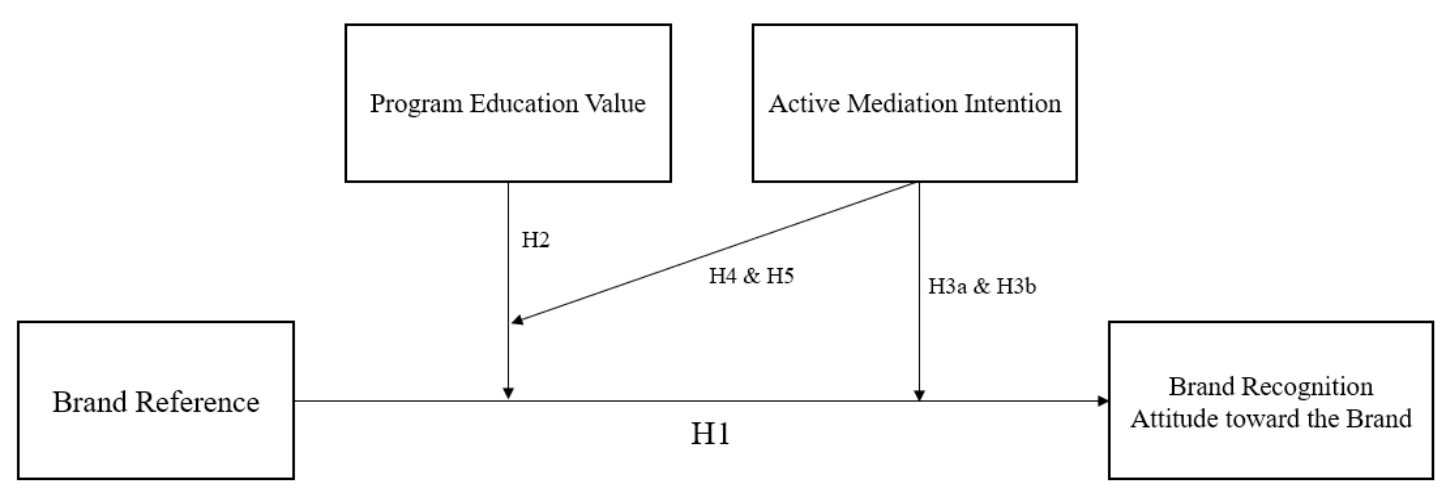

Figure 1. Conceptual map

\section{METHOD}

This study applied a 2 (brand reference: modified vs. direct) x 2 (educational value: high vs. low) x 2 (active mediation intention: high vs. low) mixed-measures experimental design to test how program educational value and active mediation intention impact parents' recognition and evaluation of product placements using modified or direct brand reference.

\section{Independent variables}

Brand Reference was a within-subject variable where participants saw both direct brand reference and modified brand reference product placements, but each stimulus only contained one product placement featuring one brand. Direct brand reference was defined as product placements using actual brand logos, whereas modified brand reference includes logos that directly imitate distinctive perceptual features such as letters, colors, and shapes of an actual brand (Van Horen \& Pieters, 2012).

For example, in Figure 2, "Kingsley's Super K" (modified brand) is the feature imitation of "Kellogg's Special K" (actual brand). All brand references were only presented visually in the stimuli with no verbal mentioning of any branding information.

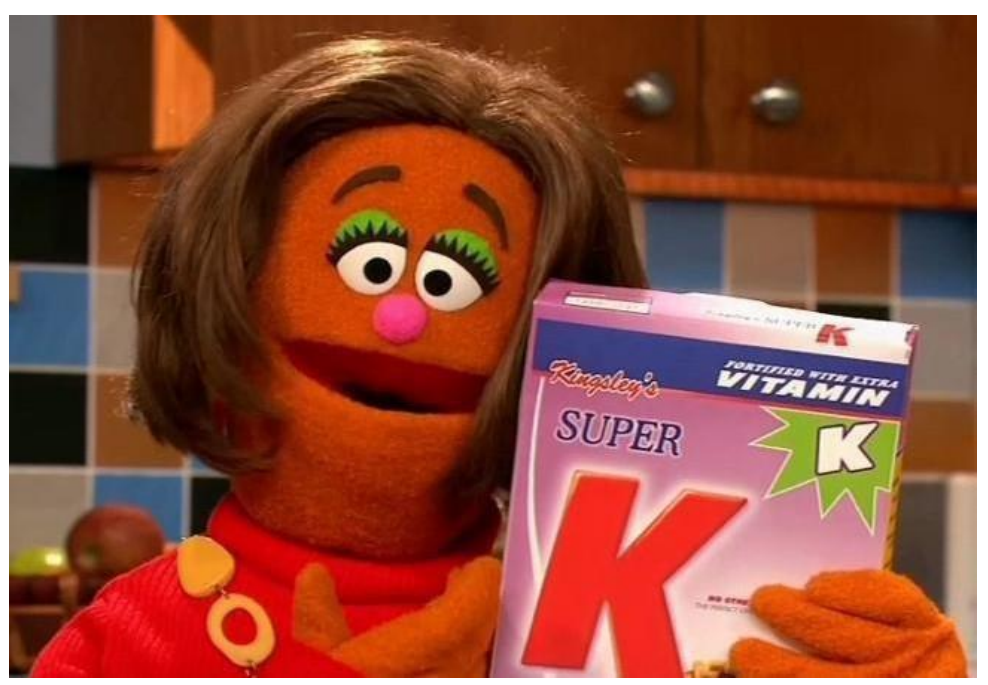

Figure 2. An Example of a Modified Brand Reference in Sesame Street.

Educational value served as a within-subject repeated measure, such that participants saw both high educational-value clips and low-educational value clips. Based on the Federal Communications Commission's (2019) definition of children's educational programming, this study defined high educational value content as programming content that helps children develop intellectual and/or cognitive abilities. Specifically, high educational value clips include content that teaches spelling and addition/subtraction. 
Operationally, the perceived educational value was verified using the question "I think this clip was educational," anchored by Strongly Disagree (1) and Strongly Agree (7).

To ensure systematic variance in perceived educational value, 11 clips were initially selected from the PBS children's educational programming lineup and other entertainment programs and movies. To gauge the difference between high and low educational value, a pretest was conducted with 121 parents rating the content of 11 clips. Pretest participants evaluated the perceived educational value, product placement obviousness, and attitude toward the clip after viewing each stimulus clip. Product placement obviousness was a control variable measured via two questions, "I think the product placement in this clip is obvious" and "I think the product placement in this clip would be recognizable for my child(ren)," using a seven-point scale anchored by Strongly Disagree (1) and Strongly Agree (7).

Attitude toward the clip was measured using a tenitem seven-point semantic differential scale, adapted from Hallahan (1999) for use in the present context, and anchored by adjectives such as boring/interesting, unappealing/appealing and uninvolving/involving. Based on the pretest results, eight clips were selected. A repeated-measures ANOVA was conducted for manipulation checks to verify the significant difference in the level of perceived educational value between high educational value and low educational value clips, $F(1$, 119) $=236.12, p<.001, \eta_{p}^{2}=.31$. The pretest results also showed the selected clips did not significantly vary in control variables including product placement obviousness $(F(1,119)=.002, p=.97)$ and attitude toward the clip $(F(1,119)=.70, p=.40)$.

Active mediation intention. Similar to past measures of advertising-related mediation intentions (Holiday et al., 2018), respondents reported the degree to which they intend to provide active mediation of the content they viewed. This was measured via three questions using a seven-point scale ranging from strongly disagree (1) to strongly agree (7), including "I intend to talk with my child in the next 30 days about product placements in content like this." Items were averaged to create a composite, with higher scores indicating greater intention to provide active mediation.

\section{Stimuli creation}

The stimuli were selected using the aforementioned pretest, in which eight clips were selected from potential stimuli. The selected clips varied in terms of their level of educational value (high vs. low) and brand reference type (modified vs. direct) resulting in four conditions (high educational value/implicit brand reference; high educational value/explicit brand reference; low educational value/implicit brand reference; low educational value/explicit brand reference). Each condition contained two clips to avoid the idiosyncratic effects of a particular message. All clips were converted to the same resolution before being inserted into the Qualtrics questionnaire. The average duration of the clips is 60.87 seconds (range $=56-84$ seconds).

\section{Dependent variables}

The effects of the independent variables were gauged on two dependent variables. Brand recognition (Wang, 2006) was measured using the question, "Did you encounter any form of advertising while viewing this segment?" anchored by Definitely Not (1) and Definitely Yes (7). Attitude toward the brand was measured using a ten-item seven-point semantic differential scale, adapted from Hallahan (1999) to address the present context, that asked participants to evaluate the brands in the clips using adjectives such as unimportant/important, unappealing/appealing, and unneeded/needed. The ten items were averaged to create a single score for attitude toward the brand. A screenshot of the product placement with an actual/modified brand logo was displayed to participants again before measuring attitude toward the brand.

\section{Participants and procedure}

The experiment was created and distributed using the online research data collection software Qualtrics. Respondents were recruited from professional Qualtrics research panels and were compensated for participation. Screening questions were placed at the beginning of the questionnaire, and only parents with at least one child currently aged in the three-to-six year-old range were eligible to participate. Seven hundred and seventy-eight people accessed the questionnaire and answered the screening questions, and 109 eligible participants completed the study. The majority of participants had two $(38.53 \%)$ or three children $(22.9 \%)$, and $76.14 \%$ of the participants indicated they were mothers. Participants reported their child(ren) spent an average of 5.31 hours $(S D=4.05)$ watching $\mathrm{TV}$, movies, or Internet content (e.g., YouTube) on a weekday. 
To avoid fatigue, participants were randomly assigned to one of two viewing groups that each consisted of a randomized presentation of four clips, with each clip representing one of the four experimental conditions. Each viewing group was presented a different series of advertisements with the same experimental conditions, which served as a repeated measure to account for message effects and to mitigate the potential confounds of within-subject priming and single message designs.

No significant difference in the dependent measurements was observed between the two viewing groups, and the analysis included answers from both viewing groups instead of reporting them separately to yield more parsimonious results.

\section{RESULTS}

Because two of the three independent variables (i.e., active mediation intention and perceived educational value) are measured as interval-level continuous variables, multiple linear regression analysis would be more appropriate for hypothesis testing than analysis of variance tests (ANOVAs).

Two linear regression models were constructed using brand recognition and attitude toward the brand as dependent variables, respectively. Program education value was standardized, and categorical variables were dummy-coded, including brand reference type $(1=$ actual brand, $2=$ modified brand $)$, and gender $(1=$ male, $0=$ female . Child age, child gender, parent age, and child media consumption were put in the first block as control variables, and brand reference type, active mediation intention, program education value, and their interaction terms were included in the second block (Aiken \& West, 1991). The brand recognition model ( $F$ $\left.=3.52, p<.001, R^{2}=.107\right)$ and attitude toward the brand model $\left(F=14.52, p<.001, R^{2}=.171\right)$ were both significant. Detailed results of these regression analyses are presented in Table 1.

Table 1. Regression analysis results

\begin{tabular}{|c|c|c|c|c|}
\hline \multirow[t]{2}{*}{ Predictors } & \multicolumn{2}{|c|}{$\begin{array}{c}\text { Regression I } \\
\text { (DV: Brand Recognition) }\end{array}$} & \multicolumn{2}{|c|}{$\begin{array}{c}\text { Regression II } \\
\text { (DV: Attitude toward the Brand) }\end{array}$} \\
\hline & $\mathrm{B}(\beta)$ & $t$ & $\mathrm{~B}(\beta)$ & $t$ \\
\hline Child age & $.049(.048)$ & 1.053 & $.046(.045)$ & .997 \\
\hline Child gender & $-.074(-.023)$ & -.499 & $-.001(.000)$ & -.006 \\
\hline Parent age & $.072(.014)$ & 1.544 & $.039(.008)$ & .856 \\
\hline Child media consumption & $.061(.024)$ & 1.289 & $.266(.110)$ & $5.86^{* * *}$ \\
\hline Block 2 & & & & \\
\hline Brand Reference & $.204(.066)$ & .191 & $2.06(.629)$ & 1.899 \\
\hline Educational value & $-2.17(-.266)$ & $-3.628 * * *$ & $.139(.121)$ & $1.978 *$ \\
\hline Active mediation & $.056(.034)$ & .503 & $-.005(-.003)$ & -.45 \\
\hline $\begin{array}{l}\text { Product reference } \mathrm{x} \\
\text { Active mediation }\end{array}$ & $.040(.034)$ & .114 & $-.430(-.458)$ & $-2.485^{*}$ \\
\hline $\begin{array}{l}\text { Product reference x Educational } \\
\text { value }\end{array}$ & $.014(.008)$ & .039 & $-.463(-.293)$ & -1.363 \\
\hline $\begin{array}{l}\text { Educational Value } \mathrm{x} \text { Active } \\
\text { mediation }\end{array}$ & $.116(.023)$ & $2.723 * *$ & $-.013(-.002)$ & -.226 \\
\hline Product Reference $\mathrm{x}$ Educational & $-.25(-.151)$ & -.44 & $.726(.127)$ & $2.194 *$ \\
\hline Total R2 & .107 & & .171 & \\
\hline Adjusted R2 & .077 & & .147 & \\
\hline
\end{tabular}

Note: $\mathrm{DV}=$ dependent variable

$* p<.05, * * p<.01 * * * p<.001$

Hypothesis 1 predicted product placements using actual brands would be as recognizable as product placements using modified brands. The effect of brand reference type on brand recognition was not significant $(B=.204, p>.05)$, indicating that brand recognition was not affected by brand reference type. Hypothesis 1 was supported.

Hypothesis 2 predicted product placements in high educational value programs would be less recognizable and lead to worse attitudes toward the product than product placements in low educational value programs. 
Results indicated the perceived educational value of a program has a significant negative effect on brand recognition $(B=-2.177, p<.001)$. Contrary to the prediction, educational value was found to have a positive effect on attitude toward the brand $(B=.139, p$ $<.05)$. Product placements in high educational value programs were less recognizable but generated a more positive attitude toward the brand. Hypothesis 2 was partially supported.

Hypothesis 3 predicted active mediation intention would moderate the impact of brand reference type on attitude but not on recognition. The results revealed a significant Brand Reference $\mathrm{x}$ Active Mediation Intention interaction effect on attitude toward the brand ( $B=-.430, p=.05$ ) but not on brand recognition. To further examine this interaction effect, the spotlight method (Fitzsimons, 2008) was applied by using one standard deviation above and below the mean score of active mediation to represent the low and high active mediation conditions. When active mediation is high, product placements using modified brands generated a more positive attitude toward the brand than product placements using actual brands (Figure 3 ).

When active mediation intention is low, product placements using actual brand images generated a better attitude toward the brand than product placements using a modified brand. Both Hypothesis $3 \mathrm{a}$ and $3 \mathrm{~b}$ were supported.

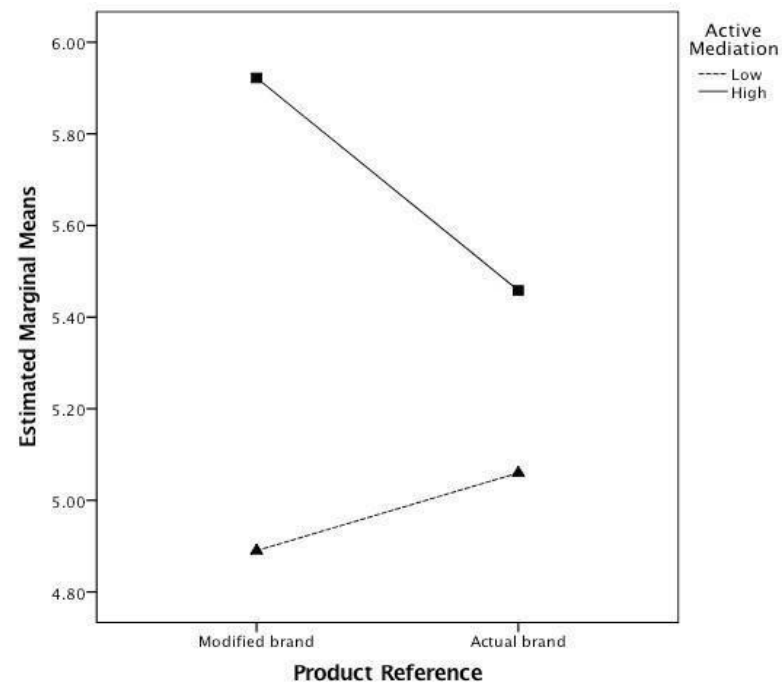

Figure 3. The Active mediation intention x Brand reference type interaction effect on attitude toward the brand

A significant Educational Value x Active Mediation Intention effect was observed on brand recognition $(B=$
$.116, p<.005)$ but not on attitude toward the brand. Follow-up analysis using the spotlight method indicated when active mediation intention is high, product placements in high educational value programs generated greater brand recognition than product placements in low educational value programs (See Figure 4).

When active mediation intention is low, product placements in low educational value programs generated better recognition than product placements in high educational value programs. Hypothesis $4 \mathrm{a}$ and $4 \mathrm{~b}$ were partially supported.

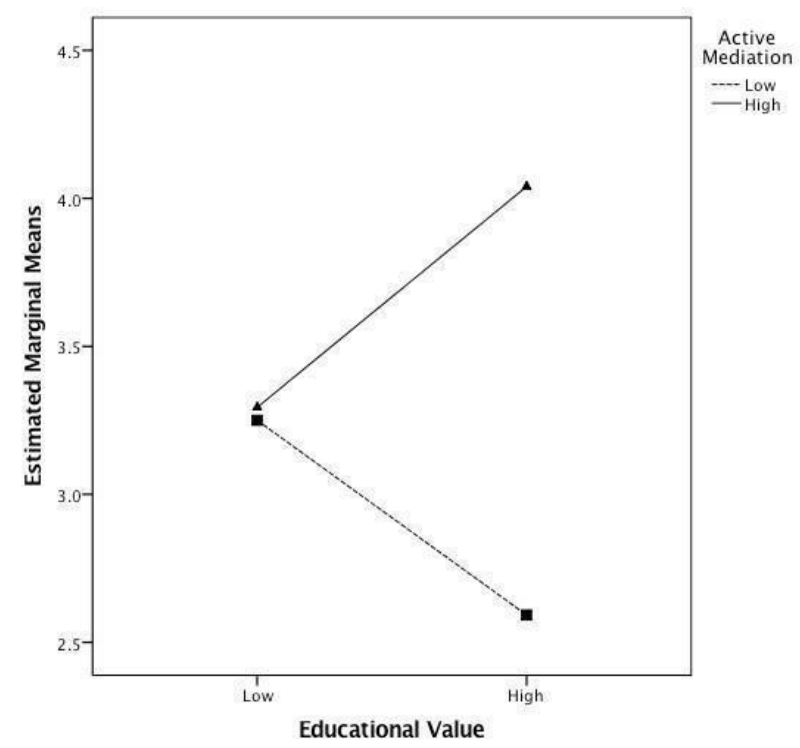

Figure 4. The Educational value $x$ Active mediation effect on product recognition

Hypothesis 5 predicted the negative perception of product placements will be most salient when participants with a high level of active mediation intention evaluate actual brands in low educational value programs. The results revealed a significant three-way interaction between brand reference type, educational value, and active mediation intention on attitude toward the brand $(B=.726, p<.05)$.

As seen in Figure 5, perceived program educational value positively correlated with attitude toward the brands, while participants with a high level of active mediation intention had the most negative attitude toward actual brands placed in low educational value programs than all other experimental conditions, supporting Hypothesis 5. 

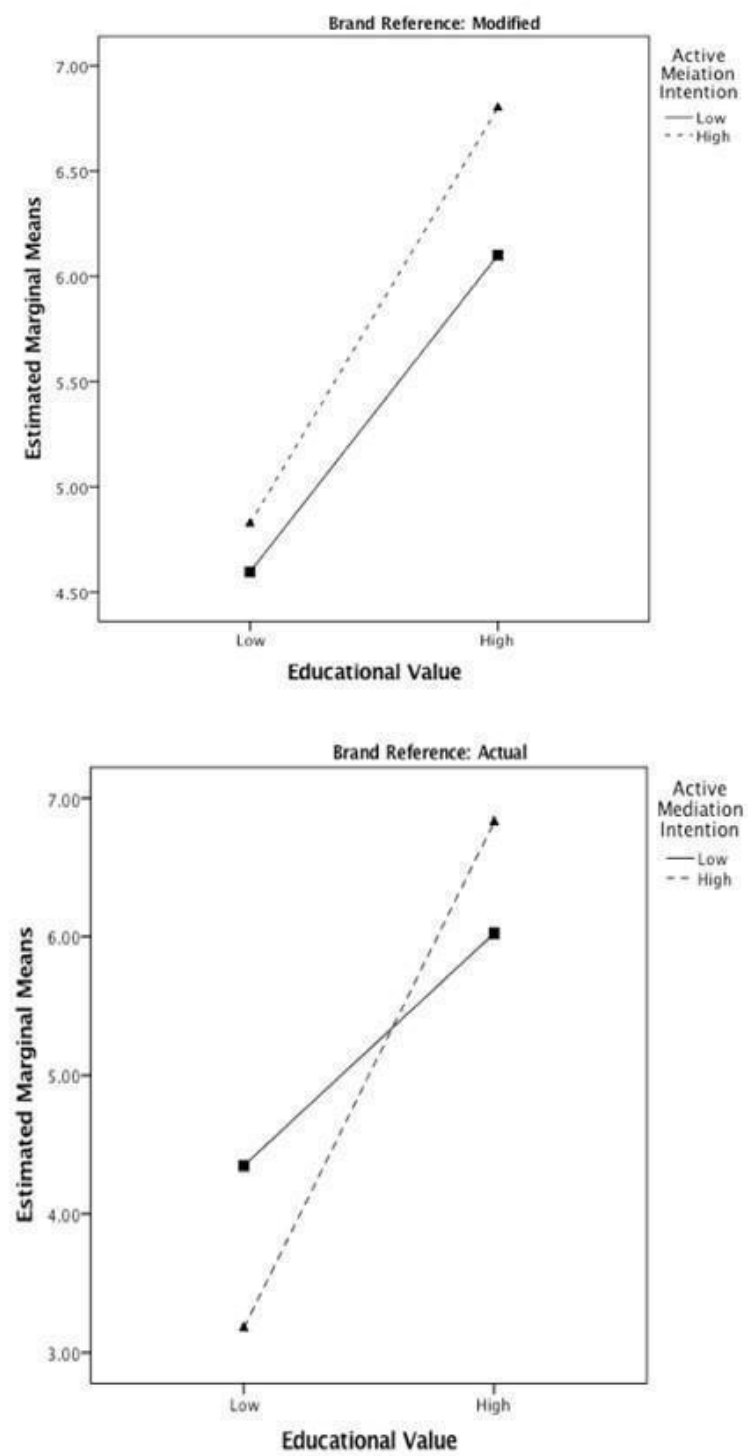

Figure 5. Three-way interaction effect between Brand reference type, Educational value, and Active mediation intention on attitude toward the brand

\section{DISCUSSION}

\section{Modified brand recognition}

The first aim of the current study is to identify whether modified brands would be as identifiable as actual brands. Results showed brand-modified product placements triggered as much recognition of actual brands as product placements that used actual brands. Schema theory suggests that this is because modified brands used distinctive perceptual features including font, colors, and shapes of actual brands, and thus the similarities between modified and actual brands helped distort the new information presented in modified brands to match schemata related to actual brands.
This finding is significant for multiple reasons. First, for advertising practitioners, using brand-modified product placements could be a viable solution to expand brand equity. Prior research suggests that viewers high in persuasion knowledge hold negative views toward product placements in general, and were concerned about their "subliminal effects" (see Evans et al., 2018). However, the current study identified that participants with high levels of active mediation intention had more positive attitudes toward brand-modified product placements than participants with low levels of active mediation intention.

This finding may be partially explained through these participants' inclinations to critically evaluate the programming so they can discuss it and its content with their children, as well as their own possible experiences of satisfaction and brand-favorable attitudes that come from resolving the brand-modified representations with the actual brands (Mohanty \& Ratneshwar, 2015). In addition, scholars have suggested that the main underlying purpose of brand modification is satire or humor (Qiao et al., 2016). Positive emotional reactions could be generated when audiences compare unexpected altered brand information with existing schemata of well-known brands. For example, one of the stimuli clips include the characters selling "Sweetie Scout Cookies" in "Diddle-E-Doos" and "Thick Mints" varieties - a modified form of the "Thin Mints" and "DoSi-Dos" varieties of "Girl Scout Cookies" - to teach counting by adding a humorous twist on the brand in a situation that is relatable to most parents and children. Thus, while using modified brands is cognitively similar to using the actual brand, the use of a modified brand could generate a positive connotation for the actual brand that serves a brand-favorable outcome.

For content producers, modified brand references in children's programs blur the line between bona fide program-related material and commercial content because they are often used for storytelling or as objects to demonstrate abstract concepts. However, it is worth noting that modified brands provide branding information on par with actual brands. While the FCC did not specifically ban the use of modified brands in children's television, content producers should approach the use of modified brands with caution. As seen in Figure 4, although modified brands generated better attitudes toward the brand than actual brands among participants with high active mediation intention, participants with low levels of active mediation intention showed a more positive attitude toward actual brands. 


\section{Educational value, product placements, and brand modifications}

A large body of research has examined the effect of message context on advertising effectiveness (for review, see Stipp, 2018). Empirical studies in this area have focused on examining whether a high level of product-program alignment (or "content-advertisement congruence") would strengthen emotional response and lead to better recall and greater ad liking (Stipp, 2018). The current research contributes to this body of literature by examining how viewers respond to product placements in educational contexts. From the theoretical perspective of EVT, expectancies for product placements are influenced by individual, relational, and context factors (Burgoon, 1993). In educational programs, the expectancies usually are associated with learning rather than entertainment or commercial purposes, and advertising of all products including educational products can be under scrutiny when displayed in educational settings (Kirkpatrick, 2000). Considering the persuasion intention and commercial purposes associated with product placements, product placements do not fit viewers' expectations for educational programs and thus should have a low product-program alignment, especially for programs with high educational value. As predicted, results indicated product placements in programs with high perceived educational value were less recognizable and generated less favorable attitudes toward the brand than product placements in programs with low educational value.

One unexpected result is that while educational value negatively correlated with brand recognition, a positive correlation was observed between attitude toward the brand and perceived educational value. One possible explanation is that all product placements in the educational clips were used for demonstration purposes that help viewers learn abstract concepts (i.e., counting and spelling). Prior studies demonstrated that product placements can enhance the narrative and perceived realism of television programs (Balasubramanian et al., 2006). Similarly, Piaget's (1929) developmental model suggests that younger children in the perceptual stage of mental development need concrete experiences to facilitate learning. Some scholars argue that using materials that are real and physically presented to children can engage children's senses because real materials can be rearranged and manipulated to demonstrate concepts concretely (Baratta-Lorton, 1976).
Research applying the concrete-to-representationalto-abstract (CRA) model also demonstrated the effectiveness of using appropriate concrete objects (e.g., sticks, beans, chips, etc.) for teaching purposes before children can demonstrate mastery of math concepts at the concrete level (Witzel, 2005). Thus, products placed in educational programs could be viewed as concrete objects that facilitate learning, resulting in positive attitudes toward them. It is possible that as the program's perceived educational value increases, participants were less likely to recognize the brands featured as product placements and more likely to view them as naturalistic objects for educational purposes, which helps explain why perceived educational value positively correlated with positive attitudes toward the brand. From the EVT perspective, evaluation of expectancy violations stems from the sum of positive and negative attributes that the communicator (i.e., media content) brought to the encounter (Burgoon, 2012). The positive attributes are evaluated based on factors such as attractiveness and ability to provide resources and help. Because product placements in educational programs could serve as resources or prompts to help demonstrate abstract concepts and to facilitate learning, they may cause audiences to give positive valenced evaluations.

\section{The role of active mediation intention in perceptions of product placements}

Parents who choose to actively mediate their children's media consumption have a heightened vigilance and scrutiny of media content (Rasmussen et al., 2016), but they are also more literate about the advertising that is taking place in the associated media content (Mendoza, 2009). This increased attention to the media programming heightens their processing of the content, and the current study showed that when parents are in this state, they actually enjoy the use of brandmodified product placements, possibly because the persuasion intention of modified brands is not as obvious as actual brands. Additionally, they experience modified brands as a type of visual metaphor, through which they gain greater appreciation for the brand by resolving or "mastering" the metaphor challenge (Han, 2018). As a result, while product placements violated viewers' expectations for educational content, modified brands could carry a more positive reward valence by serving as a type of visual metaphor, leading to a more positive attitude toward the brand. However, it is worth noting that recognition of modified brands is not affected by active mediation intention level, implying 
that the brand is readily recognizable, but that its modification incites positive affect in its audience. Practitioners should be mindful of this relationship since parents are the primary gatekeepers of their children's media exposure and their conversations with their children about the format and intent of advertising can inform their children's own evaluations of advertising (Rozendaal et al., 2016).

Getting parents to respond favorably to product placements is an important preliminary step in being able to communicate product-related information to children. The notion that parents who have intentions to discuss brand-modified product placements that they view favorably with their children, which suggests that the discussions that ensue regarding them will be positive in nature, which can positively influence their children's attitudes toward the brands (Fujioka \& Austin, 2003). From a practical perspective, these results appear to support Petty's (2009) suggestion that brand owners should actively support, encourage, or proactively identify opportunities to integrate modified versions of their brands in children's programming.

Alternatively, parents and activists should be concerned about the implications identified here. Brandmodified product placements are traditionally outside the purview of the actual brands and therefore not subject to self-regulatory programs such as the Children's Food and Beverage Advertising Initiative (CFBAI), where marketers strive to improve responsibility in food marketing practices in content that targets children (Enright \& Eskenazi, 2018). Although it may be argued that their use is artistic in nature or a form of parody or satire that has no intention to sell a product or persuade a viewer to like the actual product, for audiences, it is the perceived purpose of the brand depictions that influences consumer outcomes (Rozendaal et al., 2016), and the present results suggest that the practice serves brand-favorable outcomes. The present results additionally combine parents' responses to brand-modified product placements with their responses to the use of product placements in educational programming. The findings also identify that parents who intend to engage in active mediation of the viewed content responded more favorably to the use of brand-modified product placements in programming they perceived to be high in educational value than to the use of actual brands in content that they perceived to be low in educational value. Given these results and how brand-modified product placements are integrated into the production of children's programming that ranges from major motion pictures to educational television, as well as how parents respond positively to them and the influence that parents play in children's formation of consumer identity, individuals interested in protecting children from the undue influence that brand-modified placements have on consumers, especially children either directly or indirectly through parental communication - should focus additional effort on appealing to the producers of the content in addition to marketers. Further research is needed and encouraged to examine the nature of the active mediation that occurs in response to the modified and actual presentation of product placements in programming that is perceived with high and low educational value, as well as what mechanisms trigger the intentions to provide active mediation to this type of content, but the present findings are both elucidating and make a meaningful contribution to understanding the practice of using brand-modified product placements and their influence on viewers.

\section{REFERENCES}

Aiken, L. S., \& West, S. G. (1991). Multiple regression: Testing and interpreting interactions. Sage Publications, Inc.

Atkin, C. (1975). The effects of television advertising on children: First year experimental evidence. Department of Communications, Michigan State University.

Araque-Padilla, R., Villegas-Navas, V., \& MonteroSimo, M. J. (2019). Non-branded food placements in children's entertainment programs: A content analysis. Health Communication, 34(10), 12221229.

https://doi.org/10.1080/10410236.2019.1587690

Balasubramanian, S. K., Karrh, J. A. \& Patwardhan, H. (2006). Audience response to product placements: An integrative framework and future research agenda. Journal of Advertising, 35(3), 115-141. https://doi.org/10.2753/JOA0091-3367350308

Baratta-Lorton, M. (1976). Mathematics Their Way. Addison-Wesley.

Bijmolt, T. H., Claassen, W., \& Brus, B. (1998). Children's understanding of TV advertising: Effects of age, gender, and parental influence. Journal of Consumer Policy, 21, 171-194. https://doi.org/10.1023/A:1006831206697

Buijzen, M. (2009). The effectiveness of parental communication in modifying the relation between food advertising and children's consumption behaviour. British Journal of Developmental 
Psychology, 27, 105-121.

https://doi.org/10.1348/026151008X334719

Buijzen, M. (2014). The family's role in children's interpretation of advertising. In M. Blades, C. Oates, F. Blumberg, \& B. Gunter (Eds.), Advertising to children: New directions, new media (pp. 137-157). Palgrave Macmillan.

Burgoon, J. K. (1993). Interpersonal expectations, expectancy violations, and emotional communication. Journal of Language and Social Psychology, 12, 30-48.

https://doi.org/10.1177/0261927X93121003

Burgoon, J. K. (2012). Expectancy Violation Theory. In E. Griffin (Eds.), A first look at Communication Theory (pp. 84-92). McGraw-Hill Education.

Campbell, A. J. (2006). Restricting the marketing of junk food to children by product placement and character selling. Loyola Los Angeles Law Review, 39, 447-506.

Carrell, P. L., \& Eisterhold, J. C. (1983). Schema theory and ESL reading pedagogy. TESOL Quarterly, 17(4), 553-573. https://doi.org/10.2307/3586613

De Gregorio, F., \& Sung, Y. (2010). Understanding attitudes toward and behaviors in response to product placement. Journal of Advertising, 39(1), 83-96. https://doi.org/10.2753/JOA0091-3367390106

DeLorme, D. E. \& Reid, L. N. (1999). Moviegoers' experiences and interpretations of brands in films revisited. Journal of Advertising, 28(2), 71-95. https://doi.org/10.1080/00913367.1999.10673584

Elliott, C. (2009). Healthy food looks serious: How children interpret packaged food products. Canadian Journal of Communication, 34(3), 359-380. http://hdl.handle.net/1880/50208

Enright, M., \& Eskenazi, L. (2018). The children's food $\&$ beverage advertising initiative in action: A report on compliance and progress during 2017. Better Business Bureau. https://bbbnp-bbbp-stf-use101.s3.amazonaws.com/docs/default-

source/cfbai/2017-cfbai-progress-

report.pdf?sfvrsn=5301f28_18

Evans, N. J., Hoy, M. G., \& Childers, C. C. (2018). Parenting "YouTube Natives": The impact of preroll advertising and text disclosures on parental responses to sponsored child influencer videos. Journal of Advertising, 47(4), 326-346. https://doi.org/10.1080/00913367.2018.1544952

Federal Communications Commission (2019). Children's educational television. Federal Communications Commission. https://www.fcc.gov/consumers/guides/childrenseducational-television.

Fitzsimons, G. J. (2008). Death to dichotomizing. Journal of Consumer Research, 35(1), 5-8. https://doi.org/10.1086/589561

Fujioka, Y., \& Austin, W. E. (2003). The implications of vantage point in parental mediation of television and child's attitudes toward drinking alcohol. Journal of Broadcasting \& Electronic Media, 47(3), 418-434. https://doi.org/10.1207/s15506878jobem4703_6

Gould, S. J., Gupta, P. B., \& Grabner-Kräuter, S. (2000). Product placements in movies: A cross-cultural analysis of Austrian, French and American consumers' attitudes toward this emerging, international promotional medium. Journal of Advertising, 29(4), 41-58. https://doi.org/10.1080/00913367.2000.10673623

Hallahan, K. (1999). Content class as a contextual cue in the cognitive processing of publicity versus advertising. Journal of Public Relations Research, 11(4), 293-320. https://doi.org/10.1207/s1532754xjprr1104_02

Han, K. (2018). The influence of visual metaphor advertising types on recall and attitude according to congruity-incongruity. International Journal of Pure and Applied Mathematics, 118(19), 2435-2449. http://www.ijpam.eu/

He, M., Irwin, J. D., Sangster Bouck, L. M., Tucker, P., \& Pollett, G. L. (2005). Screen-viewing behaviors among preschoolers. American Journal of Preventive Medicine, 29(2), 120-125. https://doi.org/10.1016/j.amepre.2005.04.004

Holiday, S. (2018). Jack and Jill be nimble: A historical analysis of an "adless" children's magazine. Journal of Advertising, 47(4), 412-428. https://doi.org/10.1080/00913367.2018.1553080

Holiday, S., Bond, B. J., \& Rasmussen, E. E. (2018). Coming attractions: Parental mediation responses to transgender and cisgender film trailer content targeting adolescents. Sexuality \& Culture, 22(4), 1154-1170. https://doi.org/10.1007/s12119-0189517-3

Holiday, S., \& Davies, J. J. (2018). Animal Crackers in my... book?: Effects of shared reading on parents' memory for product placement in children's books. Journal of Family Studies, 24(3), 257-273. https://doi.org/10.1080/13229400.2016.1185022

Hudson, S., \& Elliott, C. (2013). Measuring the impact of product placement on children using digital brand integration. Journal of Food Products Marketing, 
19(3), 176-200.

https://doi.org/10.1080/10454446.2013.724370

Hudson, S., Hudson, D., \& Peloza, J. (2008). Meet the parents: A parents' perspective on product placement in children's films. Journal of Business Ethics, 80(2), 289-304. https://doi.org/10.1007/s10551-007-9421-5

Kamleitner, B., \& Jyote, A. K. (2013). How using versus showing interaction between characters and products boosts product placement effectiveness. International Journal of Advertising, 32, 633-653. https://doi.org/10.2501/IJA-32-4-633-653

Kirkpatrick, D. D. (2000, September 22). Snack foods become stars of books for children. New York Times. http://www.nytimes.com/2000/09/22/business/medi a-business-advertising-addenda-snack-foodsbecome-stars-books-for-children.html.

Lord, R. G., \& Foti, R. J. (1986). Schema theories, information processing and organizational behavior. In H. P. Sims, Jr., \& D. A. Gioria (Eds.), The thinking organization (pp. 20-48). University of Michigan Press.

Lynch, J., \& Schuler, D. (1994). The matchup effect of spokesperson and product congruency: A schema theory interpretation. Psychology \& Marketing, 11(5), 417-445. https://doi.org/10.1002/mar.4220110502

Ma, X., Shen, J., Krenn, H. Y., Hu, S., \& Yuan, J. (2016). A meta-analysis of the relationship between learning outcomes and parental involvement during early childhood education and early elementary education. Educational Psychology Review, 28(4), 771-801. https://doi.org/10.1007/s10648-015-93511

Main, K. J., Dahl, D. W., \& Darke, P. R. (2007). Deliberative and automatic bases of suspicion: Empirical evidence of the sinister attribution error. Journal of Consumer Psychology, 17(1), 59-69. https://doi.org/10.1207/s15327663jcp1701_9

Mendoza, K. (2009). Surveying parental mediation: Connections, challenges, and questions for media literacy. The Journal of Media Literacy Education, l(1), 28-41. https://digitalcommons.uri.edu/jmle/vol1/iss1/3

Mohanty, P., \& Ratneshwar, S. (2015). Did you get it? Factors influencing subjective comprehension of visual metaphors in advertising. Journal of Advertising, 44, 232-242. https://doi.org/10.1080/00913367.2014.967424

Naderer, B., Matthes, J., \& Spielvogel, I. (2019). How brands appear in children's movies. A systematic content analysis of the past 25 Years. International Journal of Advertising, 38(2), 237-257. https://doi.org/10.1080/02650487.2017.1410000

Nicovich, S. G. (2005). The effect of involvement on ad judgment in a video game environment: The mediating role of presence. Journal of Interactive Advertising, 5(2), 38-51. https://doi.org/10.1080/15252019.2005.10722105

Nikken, P., \& Jansz, J. (2014). Developing scales to measure parental mediation of young children's Internet use. Learning, Media and Technology, 39(2), 250-266. https://doi.org/10.1080/17439884.2013.782038

Ong, B. S. (1995). Should product placement in movies be banned? Journal of Promotion Management, 2(34), 159-176. https://doi.org/10.1300/J057v02n03_09

Petty, R. D. (2009). Brand parody products: Is the harm worth the howl?. Journal of Consumer Marketing, 26(2), 64-65. https://doi.org/10.1108/07363760910955351

Piaget, J. (1929). The child's conception of the world. Routledge \& Kegan Paul.

Qiao, F., Chicotsky, B., \& Billings, A. C. (2016). Loving "Mapple Store" but hating "Sprawl-Mart": A case study of brand parodies in the Simpsons. KOME - An International Journal of Pure Communication Inquiry, 4, 69-83. http://dx.doi.org/10.17646/KOME.2016.15

Rasmussen, E. E., White, S. R., King, A. J., Holiday, S., \& Densley, R. L. (2016). Predicting parental mediation behaviors: The direct and indirect influence of parents' critical thinking about media and attitudes about parent-child interactions. Journal of Media Literacy Education, 8(2), 1-21.

Reiser, R. A. Williamson, N., \& Suzuki, K. (1988). Using "Sesame Street" to facilitate children's recognition of letters and numbers. Educational Communication and Technology Journal, 36, 15-21. https://doi.org/10.1007/BF02770013

Rozendaal, E., Opree, S. J., \& Buijzen, M. (2016). Development and validation of a survey instrument to measure children's advertising literacy. Media Psychology, 19, 72-100. https://doi.org/10.1080/15213269.2014.885843

Rumelhart, D. E. (1980). Schemata: the building blocks of cognition. In R. J. Spiro, B. C. Bruce, \& W. E. Brewer (Eds.), Theoretical issues in reading comprehension (pp. 33-58). Lawrence Erlbaum Associates. 
Schmidt, T. L. \& Hitchon, J. C. (1999). When advertising and public relations converge: An application of schema to the persuasive impact of alignment. Journalism \& Mass Communication Quarterly, 76(3), 433-455.

https://doi.org/10.1177\%2F107769909907600303

Spiteri Cornish, L. (2014). 'Mum, can I play on the internet?' Parents' understanding, perception and responses to online advertising designed for children. International Journal of Advertising, 33, 437-473. https://doi.org/10.2501/IJA-33-3-437-473

Statista. (2020). Product placement spending worldwide and in selected countries in 2012, 2014, and 2019. Statista - The Media \& Advertising Portal. https://www.statista.com/statistics/261454/globalproduct-placement-spending/

Stipp, H. (2018). How context can make advertising more effective. Journal of Advertising Research, 58(2), 138-145. https://doi.org/10.2501/JAR-2018022

Van Horen, F., \& Pieters, R. (2012). Consumer evaluation of copycat brands: The effect of imitation type. International Journal of Research in Marketing, 29(3), 246-255.

https://doi.org/10.1016/j.ijresmar.2012.04.001

Van Reijmersdal, E., Neijens, P., \& Smit, E. (2005). Readers' reactions to mixtures of advertising and editorial content in magazines. Journal of Current Issues \& Research in Advertising, 27(2), 39-53. https://doi.org/10.1080/10641734.2005.10505180

Wang, A. (2006). Advertising engagement: A driver of message involvement on message effects. Journal of Advertising Research, 46(4), 355. https://doi.org/10.2501/S0021849906060429

Witzel, B. (2005). Using CRA to teach algebra to students with math difficulties in inclusive settings. Learning Disabilities: A Contemporary Journal, 3(2), 49-60. http://ies.ed.gov/ncee/wwc/study/742 